the only serious criticism one can make against this volume is that, in the absence of a formula index, the six-page subject index is much too brief and no reliable guide as to what may be found in the book. There is a twenty-page author index.

L. H. LONG

\section{GASEOUS OXIDATION PROCESSES}

\section{Oxidation and Combustion Reviews}

Vol. 1. Edited by C. F. H. Tipper. Pp. 344. (Amsterdam, London and New York: Elsevier Publishing Company, 1965.) $80 s$.

THE series Oxidation and Combustion Reviews is intended to deal with both pure and applied aspects of oxidation and combustion - a wide field in which chemistry, physics and engineering overlap. The first volume concentrates on chemical aspects of oxidation by molecular oxygen. Nevertheless, the field covered is wide; oxidation both in the gas phase and at the surfaces of solids is dealt with in six chapters by different authors.

The first chapter, "Application of the Theory of Branched Chain Reactions in Low Temperature Combustion', by R. Ben-Aim and M. Lucquin, gives a brief but useful summary of the theories of self ignition and describes some of the methods of studying it. It then discusses the application of these to real oxidation systems, dealing particularly with the cool flames of hydrocarbons and of their oxygenated derivatives. The morphology of cool flames and associated phenomena is well reviewed, but important recent developments in our knowledge of the chemical mechanism of oxidation under these conditions are given too brief a treatment.

"Oxidation Reactions Induced by Ionising Radiation", by G. Hughes, provides a useful catalogue of the reactions that occur when high energy radiation interacts with substrates containing oxygen. The author purposely excludes the irradiation of aqueous solutions, concentrat. ing on the less-well-documented reactions of pure inorganic and organic substrates.

"Gas Phase Photo-oxidation", by G. R. MeMillan and J. G. Calvert, compares photo-oxidation with thermal oxidation as a method of providing reliable information on elementary combustion reactions. Many examples are given (and critically discussed) of the derivation of rate constants and other mechanistic information from the results of photo-oxidation experiments. The elementary processes discussed include reactions of alkyl, acyl, alkylperoxy, peracyl and alkoxy radicals. The chapter is well written and logically presented.

The fourth chapter, "Oxidation Reactions involving Nitrogen Dioxide", by J.H. Thomas, is a good, up-to-date, descriptive review. It describes in detail recent kinetic work on the use of nitrogen dioxide as an oxidant, as a sensitizer and as an inhibitor in gas phase oxidation reactions. Slow combustion, flames and explosive reactions are all reviewed and particular attention is paid to the controversial nature of the initiation step in reactions involving nitrogen dioxide. Nitration reactions are, however, excluded.

In the fifth chapter, "Oxidative Degradation of High Polymers", W. L. Hawkins describes the deleterious effects on polymers of thermal and light-induced oxidative degradation and discusses methods of retarding these reactions. The "hydroperoxide chain theory", which describes the autoxidation of volatile hydrocarbons, is applied to the oxidation of hydrocarbon polymers, and ways are suggested in which this mechanism must be modified to apply to non-hydrocarbon polymers. No mathematical treatment of polymer degradation is included, but the qualitative treatment of the possible reactions involved is good.

The book ends with "The Heterogeneous Selective Oxidation of Hydrocarbons", by R. J. Sampson and
D. Shooter, which describes the effects of the physical and chemical properties of solid eatalysts in determining the selectivity of oxidation processes at their surfaces. These processes are exemplified by the oxidations of ethylene to ethylene oxide, propylene to acrolein, $\mathbf{C}_{4}$ hydrocarbons to maleic anhydride and to butadiene, and aromatic hydrocarbons to anhydrides. As well as con. sidering the basic mechanism of these processes, the authors present results of practical interest, listing 122 references to the patent literature. The chapter would benefit, however, by the inclusion of a summary of factors affecting selectivity (so far as they are known) at the expense of detailed description of results.

The volume as a whole is a mine of useful information on gaseous and gas-solid oxidation processes; it is recommended for workers in these fields. A. FISH

\section{Anthology of Orthopaedics}

By Mercer Rang. Pp. xi +243 . (Edinburgh and London: E. and S. Livingstone, Ltd., 1966.) 42s. net.

Some medical authorities dislike eponyms: others, particularly medical historians, commend them as giving honour to the discoverer of a disease or injury or its first exponent. In this well-written book Mr. Rang, senior lecturer in surgery at the University of the West Indies, studies his specialty historically, and gives us not only a brief biography of each surgeon or eponymous author, but also an extrect from the book or journal in which the condition was first described. Portrait sketches are included as well as anatomical drawings, X-ray photographs and descriptions of apparatus and splints.

Mr. Rang states in his preface that the book is not comprehensive and a number of omissions of orthopaedic eponyms will be noted by experts; but, on the whole, the more important ones are given, in addition to others less well known.

Orthopaedics is a comparatively modern specialty. Formerly, it was practised by the general surgeon who took $\mathrm{a}$ special interest in the subject. Physicians and neurologists also have contributed to orthopaedic eponyms. Hippocrates wrote a book on fractures and another on articulations. Paul of Aegina (625-690) deseribed ganglion in a tendon and its treatment. W. J. Little (1810-94) introduced tenotomy into Britain after studying Stromey'er's results in Hanover. Intending to be a surgeon, he founded the Royal Orthopaedic Hospital which is now the Royal National Orthopaedic Hospital in London. He turned from surgery to medicine, became physician to the London Hospital, and wrote on tenotomy, club foot and scoliosis. He described the spastic state caused by birth injury to the brain, which is known as Little's disease. A pioneer in specialized orthopaedics was the general practitioner, Hugh Owen Thomas (1834-91), who invented the Thomas splint and advocated prolonged rest for tuberculous joints. His nephew, Sir Robert Jones (1857-1933), specialized entirely in orthopaedic surgery from 1905 and, with Dame Agnes Hunt, founded the Robert Jones and Agnes Hunt Orthopaedic Hospital at Oswestry. Another famous pioneer was Sir Henry Gauvain (1878-1945), who obtained successful results through the open-air treatment of bone and joint tuberculosis. He described spasm of the muscles around the affected hip joint as a diagnostic sign of tuberculosis. Jones and Gauvain by their work made orthopaedics a specialty.

Artmur MacNalty

\section{The Determination of Toxic Substances in Air}

A Manual of I.C.I. Practice. Revised edition. Edited by N. W. Hanson, D. A. Reilly and H. E. Stagg. Pp. xii +200. (Cambridge: W. Heffer and Sons, Ltd., 1965.) $50 \mathrm{~s}$.

Tris book, which was first issued in 1956, has been revised by a sub-committee working under the general 